\title{
A systematic review of the South African work on the well-being of young people (2000-20 I6)
}

\author{
Kaymarlin Govender ${ }^{1,2}$, Arvin Bhana ${ }^{3,4}$, \\ Kerryn McMurray ${ }^{2}$, Jane Kelly ${ }^{5}$, Linda Theron ${ }^{6}$, \\ Anna Meyer-Weitz' ${ }^{2}$, Catherine L Ward ${ }^{5}$ \\ and Mark Tomlinson ${ }^{7}$
}

\begin{abstract}
Burgeoning research on the well-being of young people in recent years has made it difficult to identify conceptual gaps in the literature. We conducted a review of South African research in this area to better understand the use and measurement of the construct, as well as factors associated with it. The search of multiple databases identified 28 studies published in academic journals between 2000 and 2016. Within this period, studies that referred to well-being and its related subjective components varied significantly in terms of how they defined and operationalised these constructs, resulting in a fragmented body of work. The review highlights the need for a coherent research agenda in this area given the centrality of well-being research in promoting optimal outcomes in young people. Recommendations for strengthening South African research in this area are provided.
\end{abstract}

\section{Keywords}

Adolescence, psychological health, systematic review, youth well-being

\footnotetext{
'Health Economics and HIVIAIDS Research Division (HEARD), University of KwaZulu-Natal, South Africa 2Discipline of Psychology, School of Applied Human Sciences, College of Humanities, University of KwaZulu-Natal, South Africa

${ }^{3}$ Health Systems Research Unit, South African Medical Research Council, South Africa

${ }^{4}$ Centre for Rural Health, School of Nursing and Public Health, College of Health Sciences, University of KwaZulu-Natal, South Africa

${ }^{5}$ Department of Psychology, University of Cape Town, South Africa

${ }^{6}$ Department of Educational Psychology, University of Pretoria, South Africa

${ }^{7}$ Department of Psychology, Stellenbosch University, South Africa
}

\section{Corresponding author:}

Kaymarlin Govender, HEARD, College of Law and Management Sciences and Discipline of Psychology, School of Applied Human Sciences, College of Humanities, University of KwaZulu-Natal, Durban 404I, South Africa.

Email: Govenderk2@ukzn.ac.za 
In recent years, we have seen an exponential interest in the science of happiness or well-being (Seligman, 2011; Stratham \& Chase, 2010). Dodge, Daly, Huyton, and Sanders (2012) assert that the study of well-being has produced two conceptualisations of the concept. The hedonic tradition focuses on constructs such as happiness, positive affect, low negative affect, and satisfaction with life (Kahneman, Diener, \& Schwarz, 1999; Lyubomirsky \& Lepper, 1999), and the eudemonic tradition highlights positive psychological functioning and human development where happiness is experienced through challenges, growth, and purpose in life (Rogers, 1961; Ryff, 1989; Waterman, 1993). While some argue for the multi-dimensional nature of well-being (Diener, 2009; Stiglitz, Sen, \& Fitoussi, 2009), others point to the difficulty in defining and measuring the construct (Dodge et al., 2012), resulting in major challenges in identifying conceptual and informational gaps in the literature.

In South Africa, research on young people ${ }^{1}$ and well-being is appropriate given that almost $37 \%$ of the population falls between the ages of 10 and 24 (Statistics South Africa, 2012). Most of these young people are facing health and socio-economic problems associated with poverty as well as the normative age-related challenges (Coovadia, Jewkes, Barron, Sanders, $\&$ McIntyre, 2009). Because the promotion of a strengths and assets-based approach in young people is central to building long-term resilience and establishing a positive developmental trajectory, it is important to understand how the term well-being is utilised in the scientific community.

This article undertook a systematic review of studies focusing on the well-being of young people in South Africa. The purpose of this review was to synthesise published literature on well-being research in terms of (1) identifying how well-being has been conceptualised and defined, (2) identifying what indicators and measurements have been employed, and (3) examining the factors commonly associated with well-being.

\section{Method}

\section{Search strategy and selection criteria}

Systematic literature searches were conducted on PubMed, ProQuest, and the following EBSCO databases: Academic Search Premier, Africa Wide International, ATLA Religion Database with ATLASerials, Health Source: Nursing/Academic Edition, Health Source: Consumer Edition, Humanities International Complete, MEDLINE, PsycARTICLES, PsycCRITIQUES, PsycINFO, SocINDEX with Full Text, and Teacher Reference Centre. Other articles were sourced from 'Children's Worlds' (http://www.isciweb.org/).

Searches were carried out using the Boolean Search model (see Appendix 1 for search terms) and informed by the Preferred Reporting Items for Systemic Reviews and Meta Analyses (PRISMA) guidelines (Moher, Liberati, Tetzlaff, Altman, \& PRISMA Group, 2009). We recorded the number of articles identified using our search strategy, the number screened for eligibility and the final number included in our review (see Appendix 2).

Searches were limited to studies published in peer-reviewed English language journals between January 2000 and September 2016 and which included a South African population. Titles and abstracts of all articles identified in the initial search were independently screened by two reviewers using predefined criteria. Given the diversity of well-being research, we initiated the search using general terms to ensure inclusivity. Studies were considered for full-text review if the title, listed keywords, or abstract included the term 'well-being' or 'wellness' or other keywords including happiness, life satisfaction, satisfaction with life, quality of life, resilience, and positive youth development. We combined these with appropriate terms identifying participants considered to be 
young people (10-24 years) at this stage of the search (see Appendix 1 for search terms). Studies that met the initial criteria were then retrieved and further evaluated to ensure they were relevant by applying additional inclusion/exclusion criteria:

1. Studies in which primary research was conducted.

2. The participants in the study were between the ages of 10 and 24 years

3. Studies that included an assessment which related to any subjective aspect of well-being (including, e.g., psychological or spiritual well-being).

Exclusion criteria:

1. Studies where the exclusive focus was on a clinical, medical, or physical condition.

2. Studies where the exclusive focus was well-being of parents, caregivers, or significant others.

\section{Results}

\section{Study selection}

A total of 10,365 peer reviewed articles were identified in the initial search. After removal of duplicates, two reviewers conducted title and abstract screening to identify articles which met the initial screening criteria resulting in 102 studies assigned for full-text review. After assessing for eligibility, 28 studies published between January 2000 and September 2016 were selected for final inclusion in the review (see Appendix 2). Disagreements regarding inclusion were resolved by consultation with the study team.

\section{Study design of included studies}

Most of the studies reviewed used quantitative research designs (20) with 18 studies based on cross-sectional data. Only five studies employed a qualitative research design (see Table 1).

\section{Sample characteristics}

The majority of studies reviewed (18/28 studies) recruited participants through schools or higher education institutions, with some recruiting through communities, places of worship, youth organisations, and welfare services. Most used purposive or convenience samples (17/28 studies) with only two studies using stratified random sampling and one using a simple random sample.

\section{Defining well-being}

Studies under review highlighted the variability in definitions of well-being, a finding consistent with previous research (Dodge et al., 2012; Pollard \& Lee, 2003).

The studies tended either towards specific definitions of well-being (e.g., Bojuwoye \& Sylvester, 2014; Tibesigwa, Visser, \& Hodkinson, 2016) or generic descriptions (e.g., Edwards, Ngcobo, \& Pillay, 2004; Jonker, Koekemoer, \& Nel, 2015). Definitions of well-being were largely determined by the focus of each study and conceptual perspective adopted. Most adopted a mental health or psychological well-being perspective, and tended to use these terms interchangeably. Five studies defined well-being from a strengths-based perspective focusing on the positive functioning of 


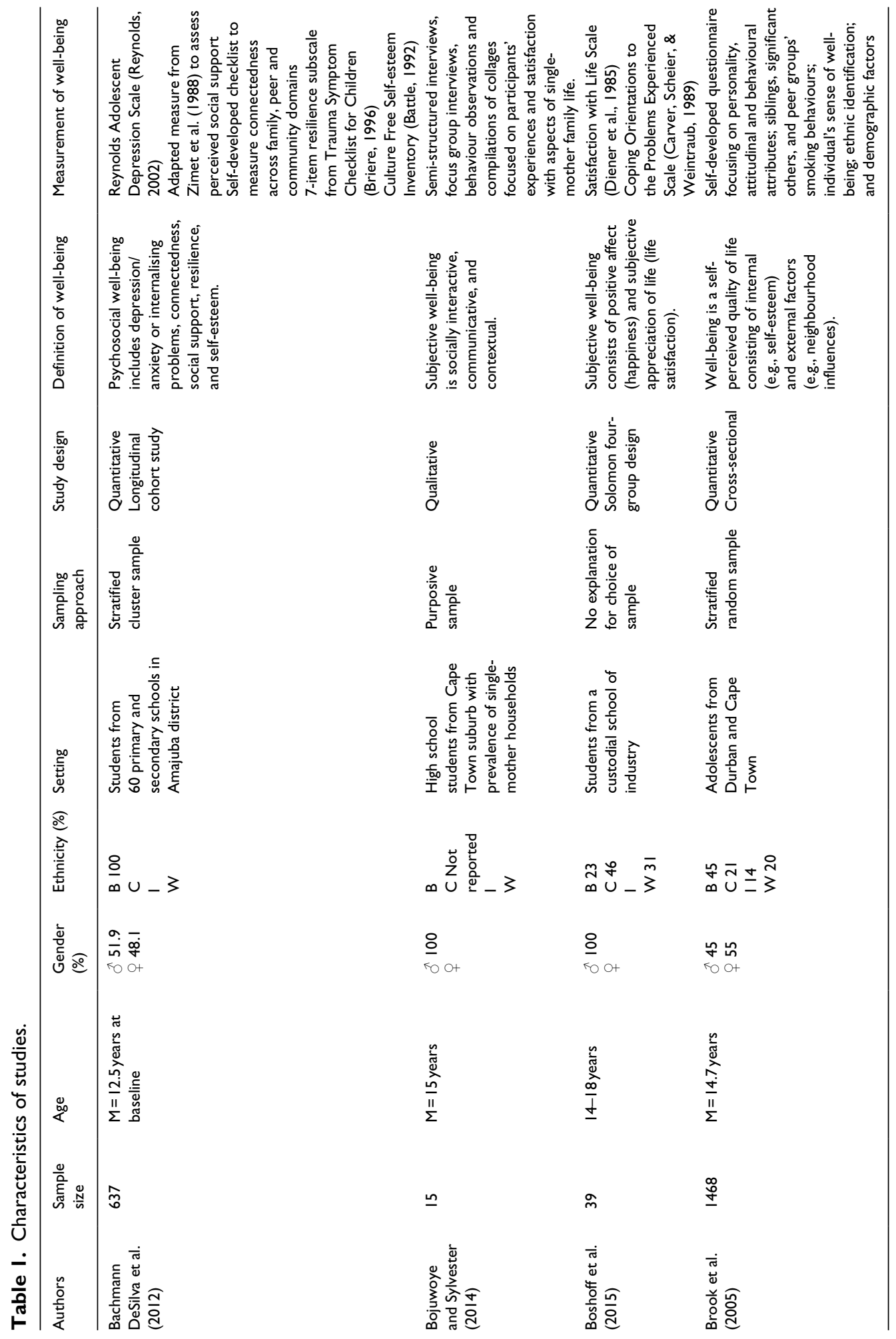




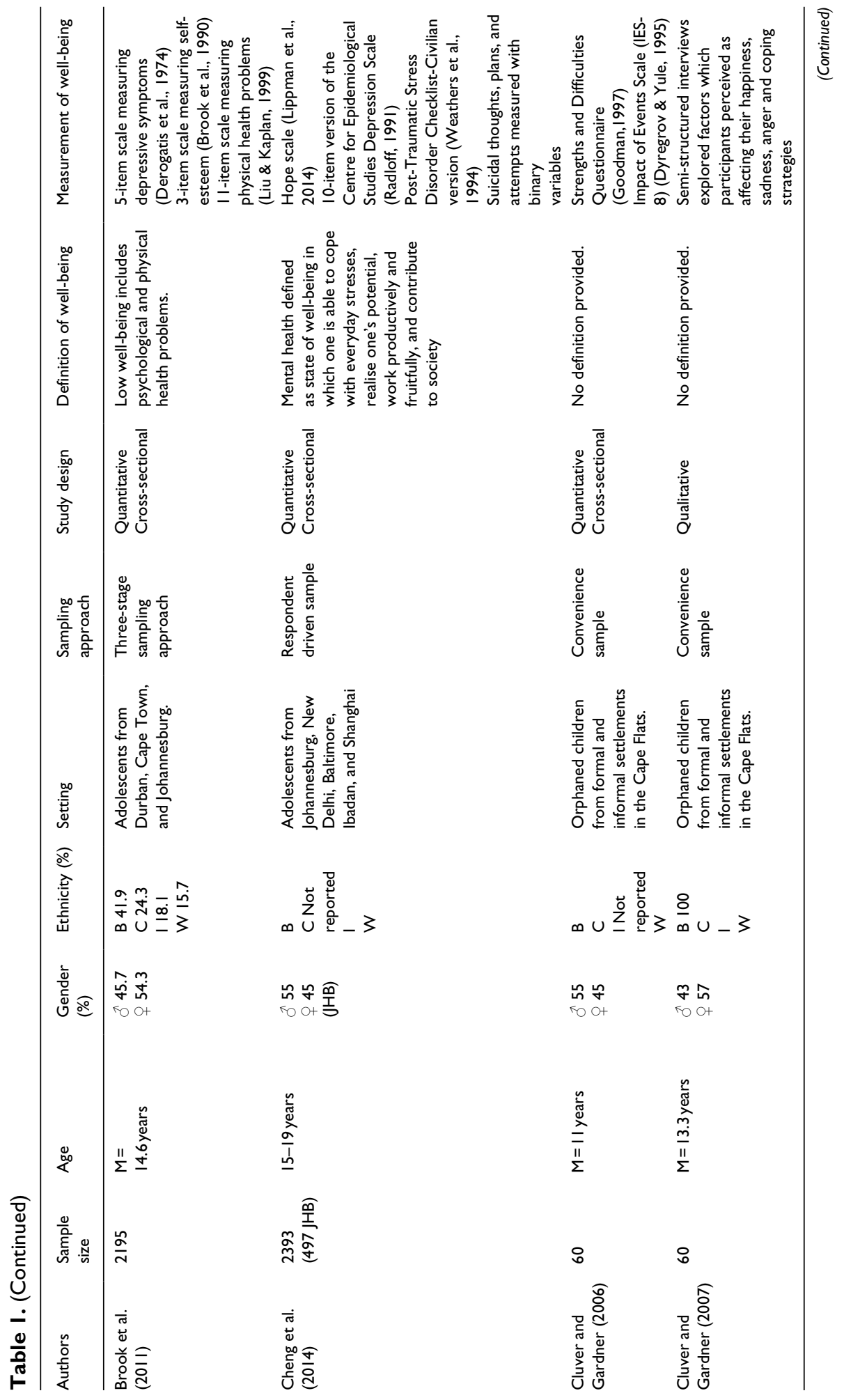




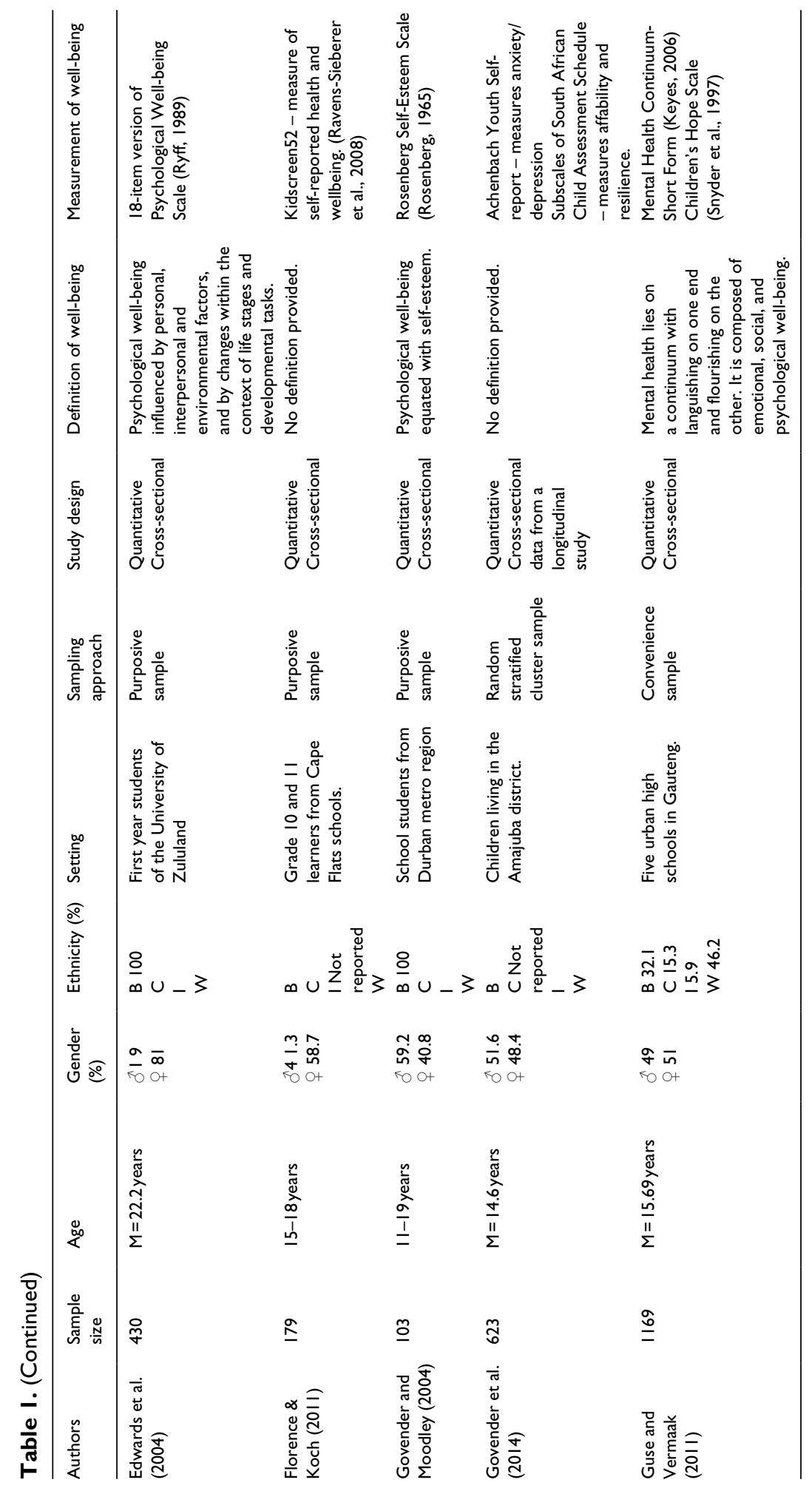




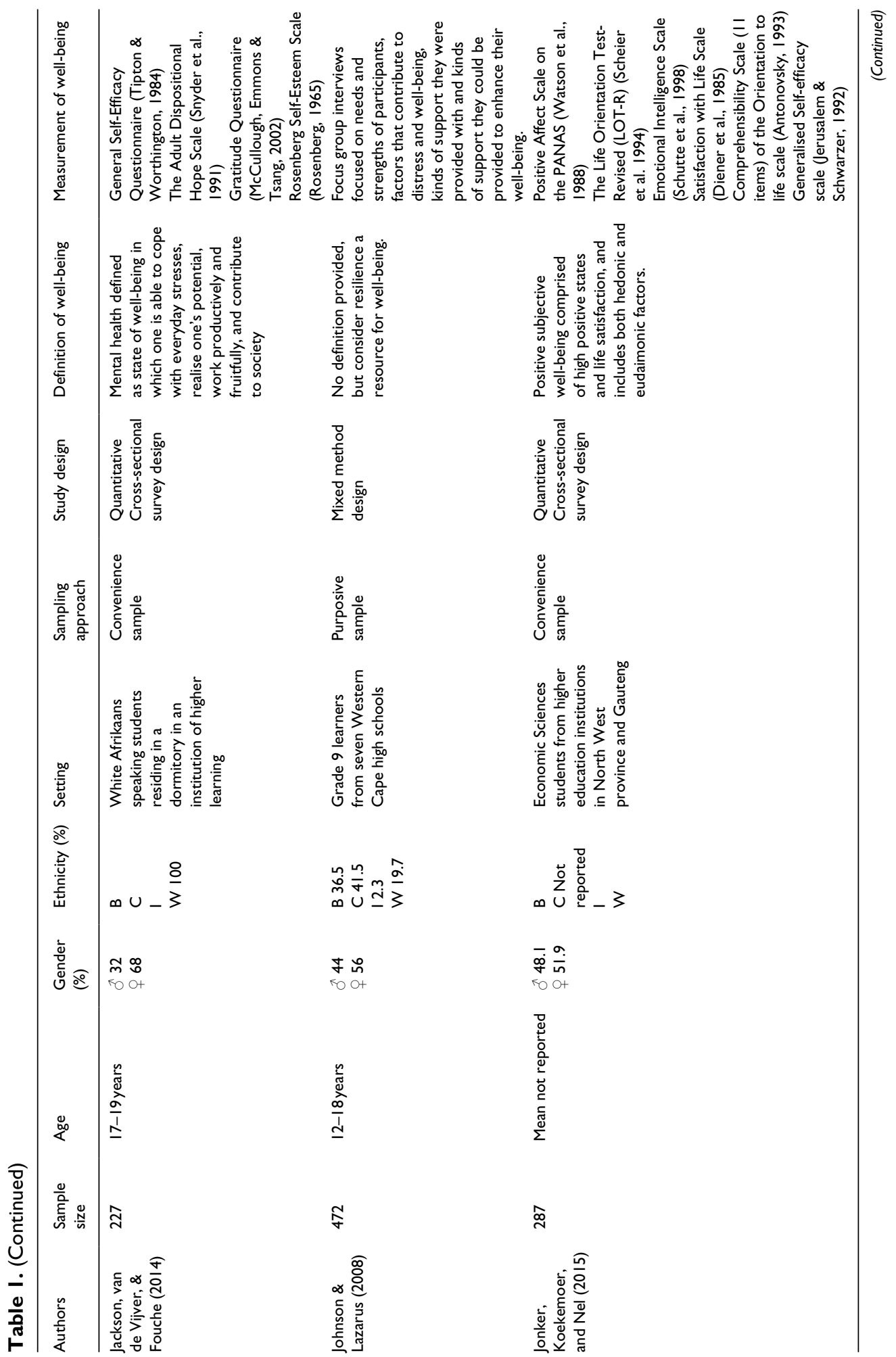




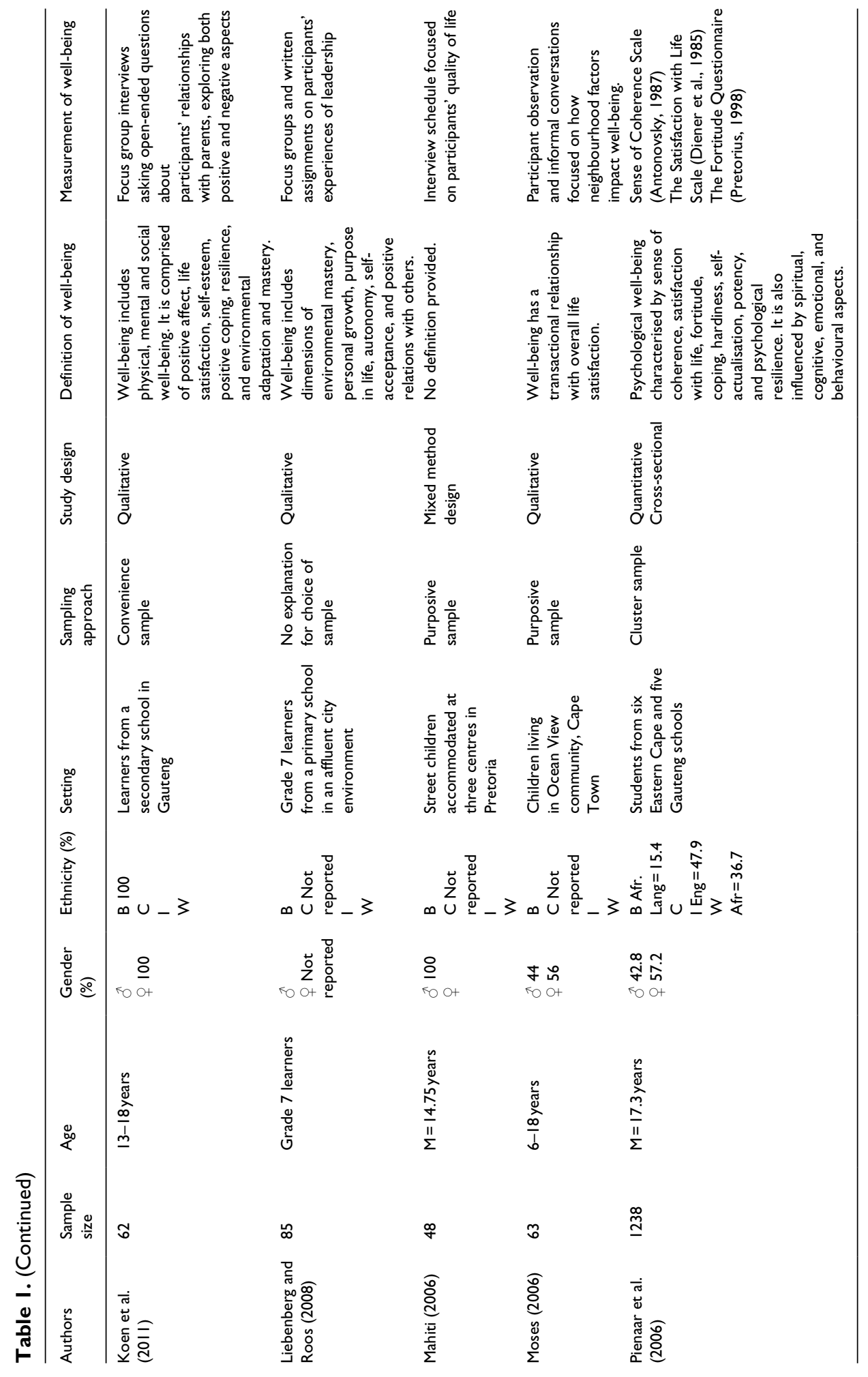




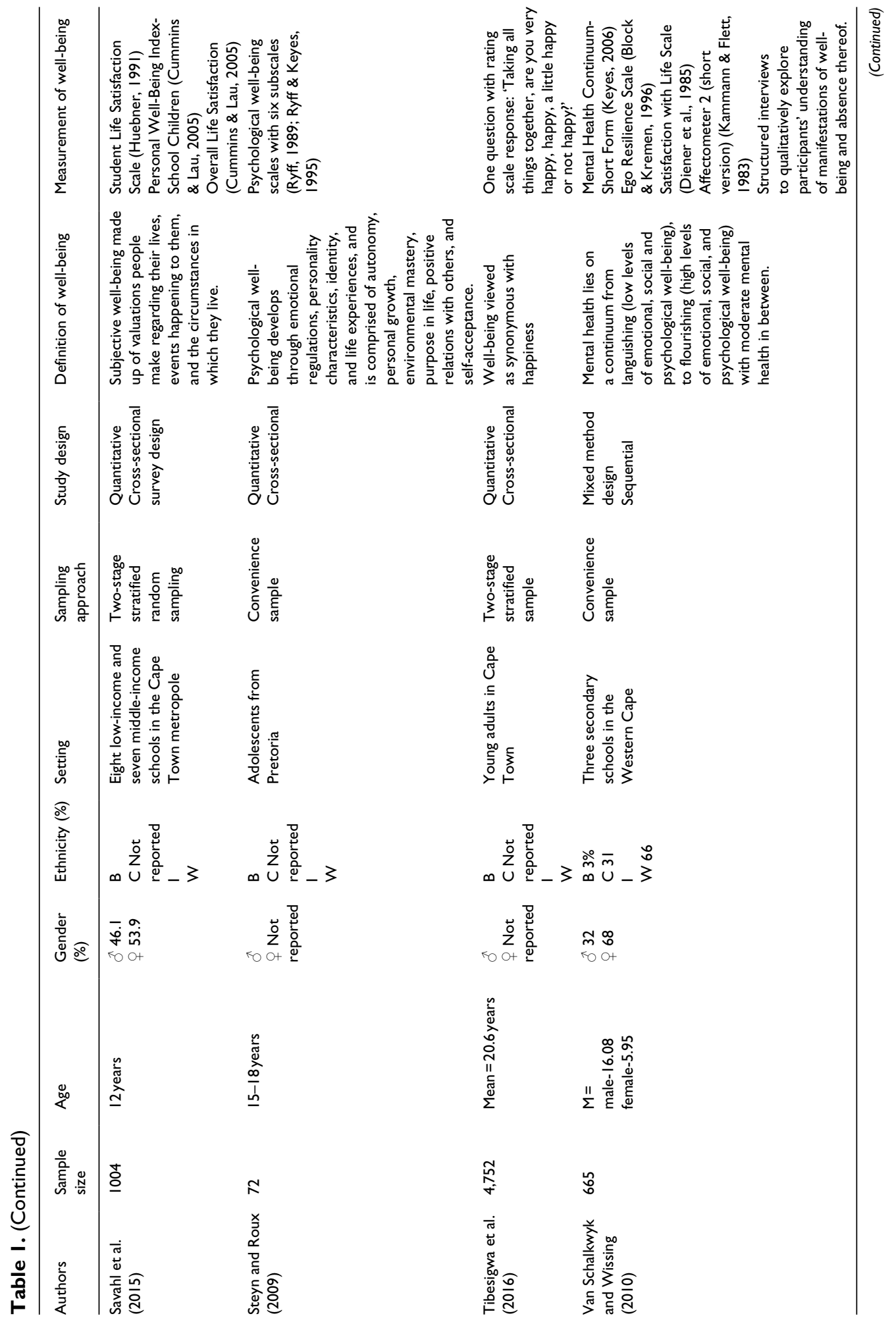




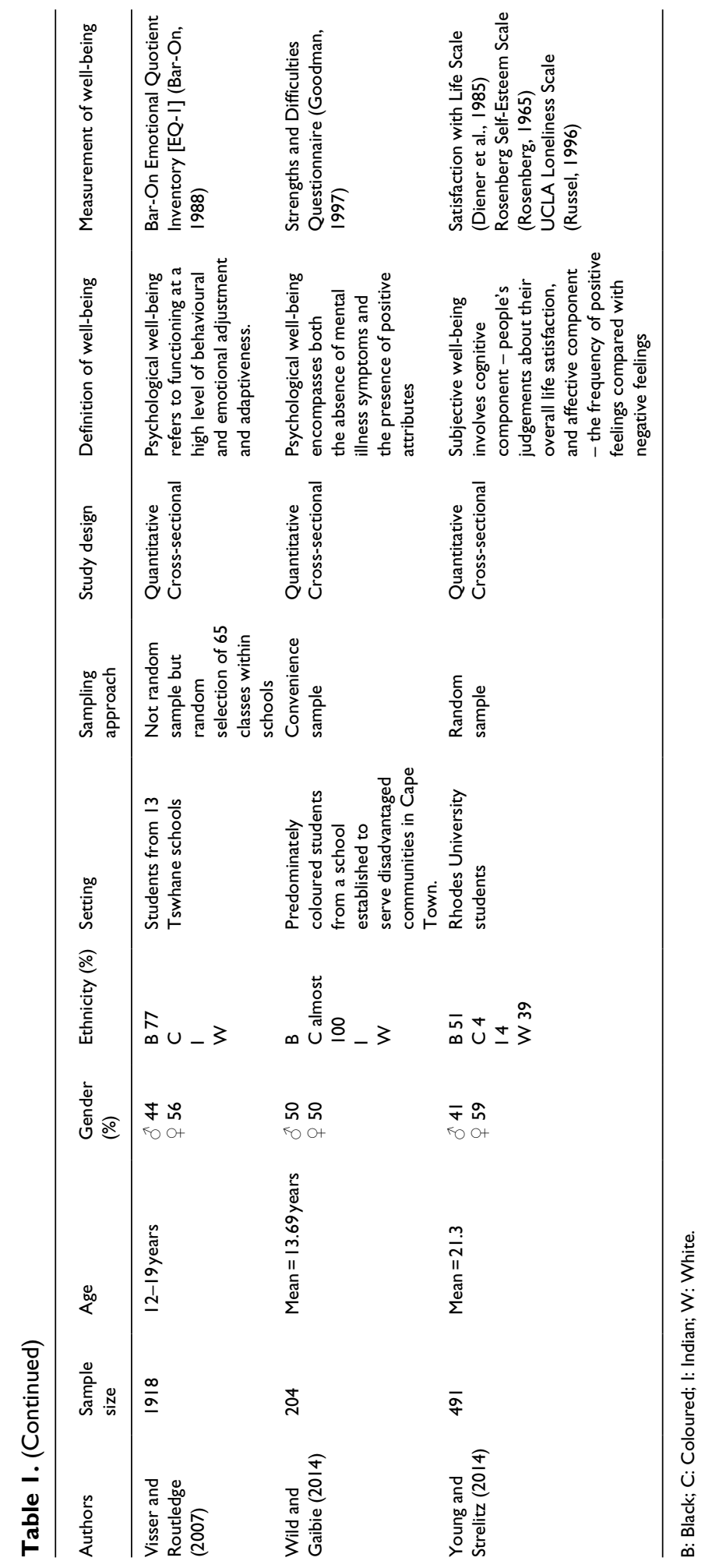


individuals (Guse \& Vermaak, 2011; Jackson et al., 2014; Jonker et al., 2015; Mahiti, 2006; Steyn \& Roux, 2009), while two studies used a low-frequency or absence-of-disorders perspective (Brook, Rubenstone, Zhang, Morojele, \& Brook, 2011; Cluver \& Gardner, 2006). Some studies adopted both a strengths- and deficits-based approach to well-being (Bachman DeSilva et al., 2012; Cheng et al., 2014; Govender, Reardon, Quinlan, \& George, 2014; Van Schalkwyk \& Wissing, 2010; Visser \& Routledge, 2007; Wild \& Gaibie, 2014).

Four studies (Edwards et al., 2004; Koen, Van Eeden, \& Venter, 2011; Liebenberg \& Roos, 2008; Steyn \& Roux, 2009) defined well-being using a multi-dimensional approach acknowledging mental, physical, and social factors. Studies by Edwards et al. (2004), Liebenberg and Roos (2008), and Steyn and Roux (2009) focused on six dimensions of well-being namely, autonomy, environmental mastery, personal growth, purpose in life, positive relations with others, and self-acceptance. This eudemonic view is synonymous with Rogers' (1961) view of the self-actualising tendency manifesting in the fully functioning person. The works by Boshoff, Grobler, and Nienaber (2015) Savahl et al. (2015), and Young and Strelitz (2014) lean towards Diener's (1984) hedonic perspective of well-being, emphasising life satisfaction and the person's affective and cognitive evaluation of his or her life.

\section{Indicators and measurement of well-being}

A number of indicators of well-being were used across the studies (see Table 1). Many of the indicators employed were strength-based constructs or positive indicators such as self-esteem, resilience, satisfaction with life, sense of coherence, and dispositional hope. While most studies used established standardised measurement tools (for instance, the Satisfaction with Life Scale - Diener, Emmons, Larson, \& Griffin, 1985 and the Rosenberg Self-esteem Scale - Rosenberg, 1965), none of these were validated in South Africa or other African settings, with few specific to well-being. Studies used multiple separate measures such as self-esteem, hope, satisfaction with life, depression, and anxiety, either by measuring well-being specifically or by using multi-dimensional assessments. Only five studies used qualitative methods exploring individual, family, and broader social domains of well-being (see Table 1).

\section{Factors associated with well-being}

The studies reviewed explored a multitude of factors associated with adolescent well-being.

Risk behaviours. Five studies explored relationships between substance abuse and well-being. Visser and Routledge (2007) and Brook, Morojele, Brook, and Rosen (2005) indicated that adolescents with a strong sense of well-being were less likely to engage in substance use. Brook et al. (2011) observed that low well-being partially mediated the association between violent victimisation and drug availability and tobacco and alcohol use. Arguing for social context, Johnson and Lazarus (2008) showed that the value of the school in promoting the well-being of adolescents was offset by the high intensity of risk behaviours of children (substance abuse and violence) living in especially impoverished areas.

Family relationships. Nine studies examined the influence of family relationships on adolescent well-being. Mother's provision of emotional security and a sense of being cared for influenced child well-being. Govender and Moodley (2004) reported that maternal presence was a significant indicator of self-esteem. They found that well-being was associated with a more authoritative parenting style among children living in informal settlements, whereas an affiliative parenting style was related to child well-being in higher income areas. 
Two studies reported negative effects of absent or detached fathers. Koen et al. (2011) supported earlier research (e.g., Louw \& Louw, 2007) that female adolescents tend to lack self-confidence, engage in riskier sexual behaviour, experience lower academic achievement, and have difficulty forming and maintaining relationships when the influence of a father is lacking. Bojuwoye and Sylvester (2014) reported dissatisfaction with social support among adolescent boys living in single-mother households, which may be due to being deprived of same-sex role models and strained relationships with opposite-sex parents.

Studies comparing the psychological well-being of orphans and non-orphans show mixed results. One study found high levels of post-traumatic stress disorder-type symptoms in orphan children living in deprived urban settlements (Cluver \& Gardner, 2006). Two studies reported that orphanhood by itself does not account for differences in well-being outcomes of adolescents. Govender et al. (2014) reported that the inability of the primary caregiver to meet basic caregiving demands and lack of communication on personal problems was a stronger determinant of child's psychosocial well-being. A similar result was reported by Cheng et al. (2014) where the presence of a caring female adult in the home was a protective factor for female mental health, and in the case of male adolescents, the presence of a caring male adult reduced the odds of depression.

The extended family was also shown to be valuable in providing a supportive surrogate caregiving source (Govender et al., 2014; Koen et al., 2011) and being protective for adolescents' emotional and behavioural well-being (Cluver \& Gardner, 2007). However, increasing the family size (especially if it is a proxy for caregiver burden) was also associated with the likelihood of child anxiety and depression among HIV orphans (Govender et al., 2014).

Social resources. Only four studies investigated the interface between non-familial support and adolescent well-being. Cheng et al. (2014) showed that perceived connection to the neighbourhood was associated with lower odds of depression and suicidal thoughts in adolescent females. Bachmann DeSilva et al. (2012) found social support from friends or significant others mitigates poor mental health and behavioural outcomes in adolescents. Moses (2006), however, argues that the positive impact of social resources cannot be over-simplified as it involves a complex interplay between the socio-economic contexts and child agency that results in optimal child outcomes.

Young and Strelitz (2014) explored social networking, social capital and well-being and found that Facebook usage was socially patterned along race and class lines and not associated with wellbeing. Liebenberg and Roos's (2008) exploration of leadership practices implemented in South African primary schools indicate that regardless of the model of leadership employed, negative self-perceptions and disrupted relationships with both peers and adults led to poor well-being.

Religiosity and conservatism. Pienaar, Beukes, and Esterhuyse (2006) found that religious fundamentalism, anti-hedonism and a conforming attitude towards authority were associated with high levels of psychological well-being, though high levels of ethnocentrism were associated with low levels of well-being.

Socio-economic conditions. Eight studies reported findings on the effects of socio-economic factors on adolescent well-being emphasising the negative impact of poverty on well-being. Cheng et al. (2014) reported that high levels of depression and post-traumatic stress was evident in adolescents who live in economically distressed areas, while Bojuwoye and Sylvester (2014) identified financial insecurity as a significant contributor to negative emotional, behavioural, and cognitive outcomes of adolescents living in single-mother homes. Both Bachmann DeSilva et al.'s (2012) and Govender et al.'s (2014) findings support the idea that living above or below the poverty threshold was a stronger indicator of psychosocial outcomes than orphanhood. Despite school being perceived as a protective factor among adolescents orphaned by AIDS, Cluver and Gardner (2007) found that 
adolescents were distressed and angered by their inability to afford school fees, uniforms, and the necessary supplies. Savahl et al. (2015) reported significant differences in satisfaction with life scores between children from low-income and middle-income communities. Quality of life was found to be threatened by a lack of access to health care, or substandard education, in addition to involvement in income-generating activities in a sample of street children (Mahiti, 2006).

Objective and subjective comparisons of income on subjective well-being show that these comparisons had a strong impact on an individuals' sense of subjective well-being with subjective comparisons having a stronger effect (Tibesigwa et al., 2016).

\section{Discussion}

Given the burgeoning literature on young people in South Africa in this area over the past 16 years, this review synthesised the evidence on definitions and conceptualisations of well-being.

Well-being is an undeniably complex concept. Our review concurs with previous research (Dodge et al., 2012; Pollard \& Lee, 2003) and indicates little consensus on the definition or measurement of well-being. The elusiveness of the term is attributed primarily to research being driven by indicators and dimensions of well-being rather than a unified conceptual understanding of the construct.

The lack of consensus on definition is partly responsible for a tendency to define well-being in unidimensional terms often ignoring the multifaceted nature of the construct with most studies approaching well-being as an absence of mental disorders. More recent work has, however, acknowledged the presence of positive functioning and support, reflecting a shift towards a strengths- and assets-based approach to well-being.

It was encouraging to note that four studies (Edwards et al., 2004; Koen et al., 2011; Liebenberg \& Roos, 2008; Steyn \& Roux, 2009) examined well-being using multiple dimensions. Not surprisingly, the absence of a universal definition of well-being is reflected in the lack of consistency in measurements employed. In addition, most of the measures used in the studies were imported from western settings. This meant that in many cases cross-cultural validity had not been established which introduces the possibility of measurement bias. In addition, design power was compromised due to a lack of representative samples, small sample sizes, as well as cross-sectional study designs. The lack of standardised assessment methods further limits comparisons of findings across contexts which is key to understanding mechanisms and processes which promote well-being in adolescents.

The five qualitative studies reviewed provided a nuanced inquiry into linkages between wellbeing and family relationships, social aspects and risk and protective factors. More research of the latter type is needed.

Our review yielded only three studies which explicitly linked resilience and well-being, with resilience research being similarly plagued by issues related to lack of consensus on definitions and measurement (Theron \& Theron, 2010; Van Rensburg, Theron, \& Rothmann, 2015). The paucity of research addressing resilience and well-being is symptomatic of the lack of common understanding of these terms (Schultze-LutterSchimmelmann, \& Schmidt, 2016). Similarly, while the incidence of risk behaviours during adolescence is well-documented, the relationship between well-being and risk behaviour appears to be underexplored in South African literature.

Accordingly, an exploration of the risk-resilience processes as well as the socio-cultural variations that leads to positive outcomes and well-being in youth is an urgent research priority. This is important for informing preventive interventions that capitalise on resilience enhancing processes to improve the quality of young people's lives.

This review has several limitations. There is a possible bias in study selection as only studies published in English peer-reviewed journals were considered, even though multiple databases were searched. Additional information from conference papers, theses, and non-peer-reviewed journals were not included. It is possible that the combination of search terms used may have not 
found all relevant literature. In addition, our review did not include studies published before 2000 which may have excluded other relevant literature, but the broad definitions used are likely to have captured most of the relevant literature after this period.

\section{Conclusion}

To the authors' knowledge this is the first study to systematically review research on adolescent wellbeing in South Africa. Despite a substantial body of literature, there are notable shortcomings: an absence of a unified and consistent definition of well-being, a lack of consistent indicators and measurement instruments, and a fragmented research focus. The review highlights several directions for future research. A priority is to address the inconsistencies in defining well-being, with an emphasis on using multi-dimensional constructs that are culturally appropriate. Equally important is the need to examine the resilience processes (definitional and measurement) that enable well-being outcomes. In terms of the latter, we require more sophisticated and longitudinal designs that accommodate associations between environmental factors and social and psychological aspects of well-being over the life course. Inclusion of biological measures (genetic, cortisol, and allostatic load differences) is also important in explaining well-being outcomes. Given the diversity of contexts in which South African youth are living in, we also need more mixed-method designs allowing for quantitative methods to be complemented by qualitative and contextually rich socio-cultural perspectives on well-being.

\section{Funding}

The author(s) declared receipt of the following financial support for the research, authorship and/or publication of this article: This study was funded by the DST-NRF Centre of Excellence (CoE) in Human Development. The views expressed and information contained within are not necessarily those of or endorsed by the CoE, which can accept no responsibility for such views or information or for any reliance placed on them. The funder had no role in study design, data collection and analysis, decision to publish, or preparation of the manuscript. Arvin Bhana and Mark Tomlinson are supported by the National Research Foundation, South Africa, and are Lead Investigators of the Centre of Excellence in Human Development, University Witwatersrand, South Africa.

\section{Note}

1. Young people are defined as being between the ages of 10 and 24 . When we refer to adolescents, 10 19 years is the accepted classification (http://apps.who.int/adolescent/seconddecade/section2/page1/ recognising-adolescence.html).

\section{References}

Antonovsky, A. (1987). Unraveling the Mystery of Health. How People Manage Stress and Stay Well. San Francisco: Jossey-Bass.

Antonovsky, A. (1993). The structure and properties of the sense of coherence scale. Social Science Medicine, $36,725-733$.

Bachman DeSilva, M., Skalicky, A. M., Beard, J., Cakwe, M., Zhuwau, T., \& Simon, J. L. (2012). Longitudinal evaluation of the psychosocial wellbeing of recent orphans compared with non-orphans in a school-attending cohort in KwaZulu-Natal, South Africa. International Journal of Mental Health Promotion, 14, 162-182.

Bar-On, R. (1988). The development of an operational concept of psychological well-being. Unpublished doctoral dissertation, Rhodes University, South Africa.

Battle, J. (1992). Culture-Free Self Esteem Inventories: Examiner's Manual (2nd ed.). Austin, TX: Pro-Ed.

Block, J., \& Kremen, A. (1996). IQ and ego resiliency: Conceptual and empirical connections and separateness. Journal of Personality and Social Psychology, 70, 349-361.

Bojuwoye, O., \& Sylvester, S. (2014). Subjective well-being of adolescent boys living in single-mother households in a Cape Town suburb, South Africa. Mediterranean Journal of Social Sciences, 5(23), 2017-2025. 
Boshoff, C., Grobler, H., \& Nienaber, A. (2015). The evaluation of an equine-assisted therapy programme with a group of boys in a youth care facility. Journal of Psychology in Africa, 25, 86-90.

Briere, J. (1996). Trauma symptom checklist for children (TSCC) professional manual. Odessa, FL: Psychological Assessment Resources.

Brook, J. S., Brook, D.W., Gordon, A.S., Whiteman, M., \& Cohen, P. (1990). The psychosocial etiology of adolescent drug use: A family interactional approach. Genetic, Social, and General Psychology Monographs, 116, 111-267.

Brook, D. W., Rubenstone, E., Zhang, C., Morojele, N. K., \& Brook, J. S. (2011). Environmental stressors, low wellbeing, smoking, and alcohol use among South African adolescents. Social Science \& Medicine, 72, 1447-1453.

Brook, J. S., Morojele, N. K., Brook, D. W., \& Rosen, Z. (2005). Predictors of cigarette use among South African adolescents. International Journal of Behavioral Medicine, 12, 207-217.

Carver, C. S., Scheier, M. F., \& Weintraub, J. K. (1989). Assessing coping strategies: A theoretically based approach. Journal of Personality and Social Psychology, 56, 267-283.

Cheng, Y., Li, X., Lou, C., Sonenstein, F. L., Kalamar, A., Jejeebhoy, S., \& Ojengbede, O. (2014). The association between social support and mental health among vulnerable adolescents in five cities: Findings from the study of the well-being of adolescents in vulnerable environments. Journal of Adolescent Health, 55(Suppl. 6), S31-S38.

Cluver, L., \& Gardner, F. (2006). The psychological well-being of children orphaned by AIDS in Cape Town, South Africa. Annals of General Psychiatry, 5, 8.

Cluver, L., \& Gardner, F. (2007). Risk and protective factors for psychological well-being of children orphaned by AIDS in Cape Town: A qualitative study of children and caregivers' perspectives. AIDS Care, 19, 318-325.

Coovadia, H., Jewkes, R., Barron, P., Sanders, D., \& McIntyre, D. (2009). The health and health system of South Africa: Historical roots of current public health challenges. The Lancet, 374, 817-834.

Cummins, R. A., \& Lau, A. D. L. (2005). Personal Wellbeing Index: School Children (PWI-SC) (3rd ed). Melbourne: Deakin University.

Derogatis, L.R., Lipman, R. S., Rickels, K., Uhlenhuth, E. H., \& Covi, L. 1974. The Hopkins Symptom Checklist (HSCL): A self-report symptom inventory. Behavioral Science, 19, 1-15.

Diener, E. (1984). Subjective well-being. Psychological Bulletin, 95, 542-575.

Diener, E. (2009). Assessing well-being: The collected works of Ed Diener. London, England: Springer.

Diener, E., Emmons, R. A., Larson, R. J., \& Griffin, S. (1985). The satisfaction with life scale. Journal of Personality Assessment, 49, 71-75.

Dodge, R., Daly, A., Huyton, J., \& Sanders, L. D. (2012). The challenge of defining wellbeing. International Journal of Wellbeing, 2, 222-235.

Dyregrov, A., \& Yule, W. (1995). Screening measures-The development of the UNICEF screening battery. Paper presented at the Fourth European Conference on Traumatic Stress. Paris, May 7-11.

Edwards, S. D., Ngcobo, H. S. B., \& Pillay, A. L. (2004). Psychological well-being in South African university students. Psychological Reports, 95, 1279-1282.

Florence, M., \& Koch, E. (2011). The difference between adolescent users and non-users of addictive substances in a low socio-economic status community: Contextual factors explored from the perspective of subjective wellbeing. South African Journal of Psychology, 41, 477-487.

Goodman, R. (1997). The Strengths and Difficulties Questionnaire: A research note. Journal of Child Psychology and Psychiatry and Allied Disciplines, 38, 581-586.

Govender, K., \& Moodley, K. (2004). Maternal support and adolescent self-esteem. Journal of Children and Poverty, 10, 37-52.

Govender, K., Reardon, C., Quinlan, T., \& George, G. (2014). Children's psychosocial wellbeing in the context of HIV/AIDS and poverty: A comparative investigation of orphaned and non-orphaned children living in South Africa. BMC Public Health, 14, 615.

Guse, T., \& Vermaak, Y. (2011). Hope, psychosocial well-being and socioeconomic status among a group of South African adolescents. Journal of Psychology in Africa, 21, 527-534.

Huebner, E. S. (1991). Initial development of the student's life satisfaction scale. School Psychology International, 12, 231-240.

Jackson, L. T. B., van de Vijver, F. J. R., \& Fouche, R. (2014). Psychological strengths and subjective wellbeing in South African white students. Journal of Psychology in Africa, 24, $299-307$. 
Jerusalem, M., \& Schwarzer, R. (1992). Self-efficacy as a resource factor in stress appraisal processes. In R. Schwarzer (Ed.), Self-efficacy: Thought Control of Action (pp. 195-213). Washington, DC: Hemisphere.

Johnson, B., \& Lazarus, S. (2008). The role of schools in building the resilience of youth faced with adversity. Journal of Psychology in Africa, 18, 19-30.

Jonker, C. S., Koekemoer, E., \& Nel, J. A. (2015). Exploring a positive SWB model in a sample of university students in South Africa. Social Indicators Research, 121, 815-832.

Kahneman, D., Diener, E., \& Schwarz, N. (1999). Well-being: Foundations of hedonic psychology. New York, NY: Russell Sage Foundation.

Keyes, C. L. M. (2006). Mental health in adolescence: Is America's youth flourishing? American Journal of Orthopsychiatry, 76, 395-402.

Koen, V., Van Eeden, C., \& Venter, C. (2011). African female adolescents' experience of parenting and their sense of well-being. Journal of Psychology in Africa, 21, 197-210.

Liebenberg, J., \& Roos, V. (2008). Preadolescent leaders: Critical reflections from a well-being perspective. South African Journal of Education, 28, 581-593.

Lippman, L., Moore, K. A., Guzman, L., Ryberg, R., McIntosh, H., Ramos, M., . . Kuhfeld, M. (2014). Flourishing Children: Defining and Testing Indicators of Positive Development. Dordrecht, Netherlands: Springer.

Liu, X., \& Kaplan, H. B. (1999). Explaining gender differences in symptoms of subjective distress in young adolescents.Stress Medicine, 15, 41-51.

Louw, D., \& Louw, A. (2007). Child and adolescent development. Bloemfontein, South Africa: University of the Free State.

Lyubomirsky, S., \& Lepper, H. (1999). A measure of subjective happiness: Preliminary reliability and construct validation. Social Indicators Research, 46, 137-155.

Mahiti, V. (2006). The quality of life of 'street children' accommodated at three shelters in Pretoria: An exploratory study. Early Child Development \& Care, 176, 253-269.

McCulluough, M. E., Emmons, R. A., \& Tsang, J. (2002). The grateful disposition: A conceptual and empirical topography. Journal of Personality and Social Psychology, 82, 112-127.

Moher, D., Liberati, A., Tetzlaff, J., Altman, D. G., \& PRISMA Group. (2009). Preferred reporting items for systematic reviews and meta-analyses: The PRISMA statement. PLoS Medicine, 6, e1000097.

Moses, S. (2006). The impact of neighbourhood-level factors on children's everyday lives, well-being and identity: A qualitative study of children living in Ocean View, Cape Town. Social Dynamics, 32, 102-134.

Pienaar, J. M., Beukes, R. B. I., \& Esterhuyse, K. G. F. (2006). The relationship between conservatism and psychological well-being in adolescents. South African Journal of Psychology, 36, 391-406.

Pollard, E. L., \& Lee, P. D. (2003). Child well-being: A systematic review of the literature. Social Indicators Research, 61, 59-78.

Pretorius, T. B. (1998). Fortitude as Stress-Resistance: Development and Validation of the Fortitude Questionnaire (FORQ). Bellville: University of Western Cape.

Radloff, L. S. (1991). The use of the Center for Epidemiological Studies of Depression Scale in adolescents and young adults. Journal of Youth Adolescence, 20, 149-166.

Ravens-Sieberer, U., Gosch, A., Abel, T., Auquier, P., Bellach, B., Diir, W., Rajmal, L., \& the European KIDSCREEN Group. (2008). Quality of life in children and adolescents: An European public health perspective. Social and Preventive Medicine, 46, 297-302.

Reynolds, W. (2002). RADS-2, Reynolds Adolescent Depression Scale Professional Manual (2nd ed.) Lutz, FL: Psychological Assessment Resources.

Rogers, C. (1961). On becoming a person: A therapist's view of psychotherapy. Boston, MA: Houghton Mifflin Harcourt.

Rosenberg, M. (1965). Society and the adolescent self-image. Princeton, NJ: Princeton University Press.

Russell, D. W. (1996). UCLA loneliness scale (Version 3): Reliability, validity, and factor structure. Journal of Personality Assessment, 66, 20-40.

Ryff, C. (1989). Beyond Ponce de Leon and life satisfaction: New directions in quest of successful aging. International Journal of Behavioral Development, 12, 35-55.

Ryff, C. D., \& Keyes, C. L. M. (1995). The structure of psychological well-being revisited. Journal of Personality and Social Psychology, 69, 719-727. 
Savahl, S., Adams, S., Isaacs, S., September, R., Hendricks, G., \& Noordien, Z. (2015). Subjective wellbeing amongst a sample of South African children: A descriptive study. Child Indicators Research, 8 , 211-226.

Scheier, M. F., Carver, C. S., \& Bridges, M. W. (1994). Distinguishing optimism from neuroticism (and trait anxiety, self-mastery, and self-esteem): A re-evaluation of the Life Orientation Test. Journal of Personality and Social Psychology, 67, 1063-1078.

Schultze-Lutter, F., Schimmelmann, B. G., \& Schmidt, S. J. (2016). Resilience, risk, mental health and wellbeing: Associations and conceptual differences. European Child \& Adolescent Psychiatry, 25, 459-466.

Schutte, N. S., Malouff, J. M., Hall, L. E., Haggerty, D. J., Cooper, J. T., Golden, C. J., \& Dornheim, L. (1998). Development and validation of a measure of emotional intelligence. Personality and Individual Differences, 25, 167-177.

Seligman, M. (2011). Florescer: Uma nova compreensão sobre a natureza da felicidade e do bem-estar [Flourishing: A new understanding of the nature of happiness and well-being]. Rio de Janeiro, Brazil: Objetiva Publicações.

Snyder, C. R., Harris, C., Anderson, J. R., Holleran, S. A., Irvin, L.M., Sigmon, S. T., . . Harney, P. (1991). The will and the ways; Development and validation of an individual-differences measure of hope. Journal of Personality and Social Psychology, 60, 570-585.

Snyder, C. R., Hoza, B., Pelham, W. E., Rapoff, M., Ware, L., Danovsky, M., . . Stahl, K. J. (1997). The development and validation of the Children's Hope Scale. Journal of Pediatric Psychology, 22, 399-421.

Statistics South Africa. (2012). Census 2011: Census in brief Pretoria. Retrieved from http://www.statssa. gov.za/census/census_2011/census_products/Census_2011_Census_in_brief.pdf

Steyn, B., \& Roux, S. (2009). Aggression and psychological well-being of adolescent Tae Kwon do participants in comparison with hockey participants and a non-sport group. African Journal for Physical, Health Education, Recreation and Dance, 15, 32-43.

Stiglitz, J., Sen, A., \& Fitoussi, J. P. (2009). Report by the commission on the measurement of economic performance and social progress. Retrieved from http://ec.europa.eu/eurostat/documents/118025/118123/ Fitoussi+Commission+report

Stratham, J., \& Chase, E. (2010). Childhood wellbeing - A brief overview. Loughborough: Childhood Wellbeing Research Centre.

Theron, L. C., \& Theron, A. M. (2010). A critical review of studies of South African youth resilience, 1990 2008. South African Journal of Science, 106(7-8), 1-8.

Tibesigwa, B., Visser, M., \& Hodkinson, B. (2016). Effects of objective and subjective income comparisons on subjective wellbeing. Social Indicators Research, 128, 361-389.

Tipton, R. M., \& Worthington, E. L. (1984). The measurement of generalized self-efficacy: A study of construct validity. Journal of Personality Assessment, 48, 545-548.

Van Rensburg, A., Theron, L., \& Rothmann, S. (2015). A review of quantitative studies of South African youth resilience: Some gaps. South African Journal of Science, 111, 1-9.

Van Schalkwyk, I., \& Wissing, M. (2010). Psychosocial well-being in a group of South African adolescents. Journal of Psychology in Africa, 20, 53-60.

Visser, M., \& Routledge, L.-A. (2007). Substance abuse and psychological well-being of South African adolescents. South African Journal of Psychology, 37, 595-615.

Waterman, A. (1993). Two conceptions of happiness: Contrasts of personal expressiveness (eudaimonia) and hedonic enjoyment. Journal of Personality and Social Psychology, 64, 678-676.

Watson, D., Clark, L. A., \& Tellegen, A. (1988). Development and validation of brief measures of positive and negative affect: The PANAS scales. Journal of Personality and Social Psychology, 54, 1063-1070.

Weathers, F. W., Litz, B. T., Huska, J. A., \& Keane, T. M. (1994). PTSD Checklist -Civilian version. Boston: National Center for PTSD, Behavioral Science Division.

Wild, L. G., \& Gaibie, F. (2014). Grandparental involvement and South African adolescents' psychological well-being. Journal of Intergenerational Relationships, 12, 425-441.

Young, C., \& Strelitz, L. (2014). Exploring patterns of Facebook usage, social capital, loneliness and wellbeing among a diverse South African student sample. Communicare, 33, 57-72.

Zimet, G. D., Dahlem, N. W., Zimet, S. G., \& Farley, G. K. (1988). The multidimensional scale of perceived social support. Journal of Personality Assessment, 52, 30-41. 


\section{Appendix I}

\section{Search terms}

(adolescen* odds ratio [OR] youth OR child OR boys OR girls OR teen*) AND (well-being OR wellness) AND ('South Africa')

(adolescen* OR youth OR child OR boys OR girls OR teen*) AND (well-being OR wellness) AND resilience AND ('South Africa')

(adolescen* OR youth OR child OR boys OR girls OR teen*) AND (well-being OR wellness) AND (life satisfaction OR satisfaction with life) AND ('South Africa')

(adolescen* OR youth OR child OR boys OR girls OR teen*) AND (well-being OR wellness) AND (quality of life) AND ('South Africa')

(adolescen* OR youth OR child OR boys OR girls OR teen*) AND (well-being OR wellness) AND (happiness) AND ('South Africa')

(adolescen* OR youth OR child OR boys OR girls OR teen*) AND ('positive mental health' OR 'positive youth development') AND ('South Africa')

\section{Appendix 2}

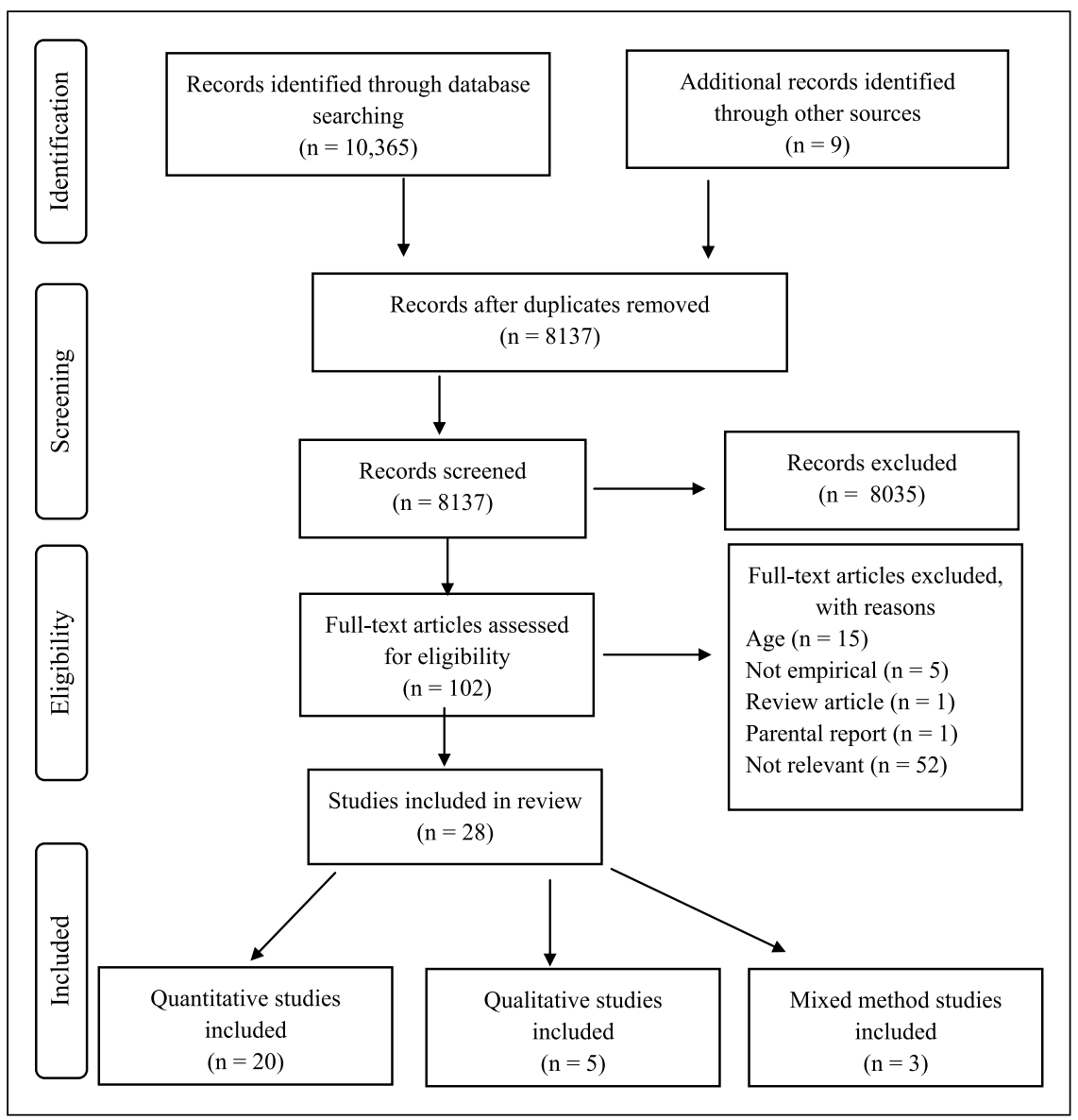

Flow diagram of selection process. 